\title{
Influence of sugar type on the bioavailability of cocoa flavanols
}

\author{
Ana Rodriguez-Mateos ${ }^{1}$, Maria Jose Oruna-Concha ${ }^{1}$, Catherine Kwik-Uribe ${ }^{2}$, Alberto Vidal ${ }^{3}$ and \\ Jeremy P. E. Spencer ${ }^{1 *}$ \\ ${ }^{1}$ Molecular Nutrition Group, School of Chemistry, Food and Pharmacy, University of Reading, Reading RG6 6AP, UK \\ ${ }^{2}$ Analytical and Applied Sciences Group, Mars, Incorporated, Hackettstown, NJ 07840, USA \\ ${ }^{3}$ Department of Mathematics and Statistics, School of Mathematics and Physical Sciences, University of Reading, Reading \\ $R G 6$ GAP, UK
}

(Submitted 14 November 2011 - Final revision received 16 January 2012 - Accepted 25 January 2012 - First published online 7 March 2012)

\section{Abstract}

The beneficial effects of cocoa on vascular function are mediated by the absorption of monomeric flavanols into the circulation from the small intestine. As such, an understanding of the impact of the food matrix on the delivery of flavanols to the circulation is critical in assessing the potential vascular impact of a food. In the present study, we investigated the impact of carbohydrate type on flavanol absorption and metabolism from chocolate. A randomised, double-blind, three-arm cross-over study was conducted, where fifteen volunteers were randomly assigned to either a high-flavanol $(266 \mathrm{mg})$ chocolate containing maltitol, a high-flavanol $(251 \mathrm{mg})$ chocolate with sucrose or a low-flavanol $(48 \mathrm{mg}$ ) chocolate with sucrose. Test chocolates were matched for micro- and macronutrients, including the alkaloids theobromine and caffeine, and were similar in taste and appearance. Total flavanol absorption was lower after consumption of the maltitolcontaining test chocolate compared with following consumption of its sucrose-containing equivalent $(P=0 \cdot 002)$. Although the $O$-methylation pattern observed for absorbed flavanols was unaffected by sugar type, individual levels of unmethylated ( - )-epicatechin metabolites, 3'-O-methyl-epicatechin and 4'-O-methyl-epicatechin metabolites were lower for the maltitol-containing test chocolate compared with the sucrose-containing equivalent. Despite a reduction in the total plasma pool of flavanols, the maximum time $\left(T_{\max }\right)$ was unaffected. The present data indicate that full assessment of intervention treatments is vital in future intervention trials with flavanols and that carbohydrate content is an important determinant for the optimal delivery of flavanols to the circulation.

\section{Key words: Cocoa flavanols: Absorption: Metabolism: Sugars: Maltitol}

Evidence suggests that the regular consumption of diets rich in fruit and vegetables and/or beverages, such as tea and wine, may have cardiovascular benefits ${ }^{(1-4)}$ and that flavonoids contained within these foods may be the components responsible for function ${ }^{(4-10)}$. Cocoa and cocoa-based products, such as chocolate, are a potentially rich source of one flavonoid subgroup called flavanols ${ }^{(11)}$, and in certain settings, these foods have been found to be important contributors to the total dietary intake of flavonoids ${ }^{(5)}$. Although the health benefits of flavanols in humans are accumulating, there is insufficient evidence to claim a clear and undisputed positive health effect relating to their consumption, particularly with regard to long-term ingestion and health. In addition, chocolate products are usually rich in sugar and saturated fats, which might counteract the beneficial effects exerted by the flavanols they contain. At present, much of the strongest data, particularly with regard to cardiovascular benefits, are based on short-term, small-scale human studies; where appropriate, well-characterised controls have been utilised.

Considering the limitations mentioned above, cocoaderived flavanols have been shown to be capable of promoting clinically significant improvements in cardiovascular health through their potential to lower blood pressure ${ }^{(7,12-15)}$, improve endothelial function ${ }^{(16-21)}$, inhibit platelet aggregation $^{(22-24)}$ and curtail the inflammatory response ${ }^{(25-27)}$ following oral intake. As such, there has been much interest in understanding the factors that define the liberation (from foods), absorption, metabolism, distribution and excretion of flavanols in vivo ${ }^{(19,28-34)}$, in order to better understand the bioavailability of flavanols in the context of different food matrices, and ultimately, to enable improved food design for health. An important aspect of flavanol delivery relates to the influence of the food matrix on the liberation of flavanols from the food before absorption. For example, the physical

Abbreviations: 3ME, 3'-O-methyl-epicatechin; 4ME, 4'-O-methyl-epicatechin; CF, cocoa flavanol.

*Corresponding author: Dr J. P. E. Spencer, email j.p.e.spencer@reading.ac.uk 
composition of the cocoa-containing product might have an impact on plasma flavanol kinetics ${ }^{(32)}$. While the majority of the published literature on the effects of food matrices on cocoa flavanol (CF) absorption has focused on the influence of dairy products on absorption and metabolism ${ }^{(34,35-38)}$, there has also been interest in the impact of carbohydrates on the biotransformation of flavanols. Indeed, the extent, and rate, of flavanol absorption appears to be affected by concurrent consumption of bread, sugar or grapefruit juice, whereas no specific protein-flavanol or lipid-flavanol interactions have been reported with respect to flavanol absorption/metabolism ${ }^{(29)}$. In addition, co-administration of flavanols with carbohydrate-rich foods appears to lead to a significant increase in plasma flavanol concentrations and an acceleration of their renal elimination ${ }^{(29)}$. While these results suggest that the presence of carbohydrate in the food matrix may increase overall flavanol absorption, these studies were not designed to specifically assess the impact of sugar on flavanol absorption. The present study has been designed to specifically investigate the impact of sugar type by use of two solid chocolates matched for physical structure, lipid, milk and flavanol content but differing in that one contains sucrose and the other the carbohydrate substitute, maltitol.

\section{Experimental}

\section{Materials}

Unless otherwise stated, all chemicals and reagents were obtained from Sigma-Aldrich Company Limited or Thermo Fisher Scientific. Flavanol standards were a gift from Mars, Inc. Specialised HPLC solvents were purchased from Hichrom and HPLC columns were from Phenomenex.

\section{Flavanol-containing test chocolates}

The test chocolates were in the form of solid chocolate bars, which were supplied by Mars, Inc. The serving size of each bar was $25 \mathrm{~g}$. All test chocolates were standardised for their total CF content and profile, and aside from the energy and carbohydrate content of the maltitol product, all test products were closely matched for equal macro- and micronutrient content, energy load, and theobromine and caffeine levels (Table 1). All chocolate bars were similar in taste and were supplied individually wrapped and labelled with a random three-digit code. Each $25 \mathrm{~g}$ serving contained $48 \mathrm{mg}$ (low-CF, sugar-sweetened chocolate), $251 \mathrm{mg}$ (high-CF, sugar-sweetened chocolate) or $266 \mathrm{mg}$ (high-CF, maltitol-sweetened chocolate) of total CF. The amount of total CF is defined as the sum of all monomeric flavanols and their oligomeric (dimer to decamer) derivatives (Table 1). The amount of epicatechin, the major flavanol monomer, present in the chocolates was $8 \mathrm{mg}$ for the low-CF sweetened chocolate, $54 \mathrm{mg}$ for the high-CF sweetened chocolate and $58 \mathrm{mg}$ for the high-CF, maltitol-sweetened chocolate. In addition to the added sugar reported, a small amount of endogenous carbohydrate from the chocolate liquor is present in all the chocolate bars.

\section{Intervention study subjects}

A total of fifteen healthy volunteers (nine women and six men) with a mean age of 26.9 (SEM 3.4) years and a BMI between 18.1 and $26.9 \mathrm{~kg} / \mathrm{m}^{2}$ (mean BMI $22.7($ sem 3.5$) \mathrm{kg} / \mathrm{m}^{2}$ ) were recruited. All female volunteers were self-reported premenopausal (stable and regular menstrual cycles). Volunteers were assessed before the start of the trial for good health and were selected according to certain inclusion and exclusion criteria. Inclusion criteria for participation in the study were as follows: signed consent form; aged between 18 and 40 years; in good general health; not pregnant or lactating; no allergy to milk products or sensitivity to alkaloids/caffeine; no gastrointestinal disorders (e.g. chronic constipation, diarrhoea, inflammatory bowel disease, irritable bowel syndrome or other chronic gastrointestinal complaints); not diabetic or suffering from hypertension $(140 / 90 \mathrm{mmHg})$; no anaemia

Table 1. Compositional analysis of the cocoa flavanol bars

\begin{tabular}{lccc}
\hline Analysis & $\begin{array}{c}\text { Sucrose } \\
\text { low-flavanol bar }\end{array}$ & $\begin{array}{c}\text { Sucrose } \\
\text { high-flavanol bar }\end{array}$ & $\begin{array}{c}\text { Maltitol } \\
\text { high-flavanol bar }\end{array}$ \\
\hline Energy values $(\mathrm{kcal} / 100 \mathrm{~g})$ & 519 & 516 & 445 \\
Energy values $(\mathrm{kJ} / 100 \mathrm{~g})$ & 2163 & 2149 & 1839 \\
Protein $(\mathrm{g} / 100 \mathrm{~g})$ & $8 \cdot 10$ & $8 \cdot 46$ & $8 \cdot 44$ \\
Fat $(\mathrm{g} / 100 \mathrm{~g})$ & $35 \cdot 3$ & $34 \cdot 5$ & $34 \cdot 3$ \\
Carbohydrates $(\mathrm{g} / 100 \mathrm{~g})$ & $42 \cdot 4$ & $43 \cdot 0$ & $43 \cdot 1$ \\
Sugars $(\mathrm{g} / 100 \mathrm{~g})$ & $39 \cdot 0-39 \cdot 4$ & $39 \cdot 0-39 \cdot 4$ & $0 \cdot 5-0 \cdot 9$ \\
Sucrose $(\mathrm{g} / 100 \mathrm{~g})$ & $39 \cdot 0$ & $39 \cdot 0$ & $0 \cdot 5$ \\
Polyols $(\mathrm{g} / 100 \mathrm{~g})$ & - & - & $43 \cdot 5-46 \cdot 0$ \\
Maltitol $(\mathrm{g} / 100 \mathrm{~g})$ & - & - & $43 \cdot 5$ \\
Fibres $(\mathrm{g} / 100 \mathrm{~g})$ & $9 \cdot 2$ & $8 \cdot 8$ & $8 \cdot 9$ \\
Moisture $(\mathrm{g} / 100 \mathrm{~g})$ & $1 \cdot 00$ & $1 \cdot 11$ & $1 \cdot 20$ \\
Ash $(\mathrm{g} / 100 \mathrm{~g})$ & $3 \cdot 18$ & $2 \cdot 41$ & $2 \cdot 21$ \\
Na $(\mathrm{mg} / 100 \mathrm{~g})$ & $5 \cdot 1$ & $2 \cdot 2$ & $2 \cdot 1$ \\
Caffeine $(\mathrm{mg} / 100 \mathrm{~g})$ & 58 & 102 & 102 \\
Theobromine $(\mathrm{mg} / 100 \mathrm{~g})$ & 643 & 709 & 710 \\
Cocoa flavanols $(\mathrm{mg} / 100 \mathrm{~g})$ & 190 & 1005 & 1064 \\
Epicatechin $(\mathrm{mg} / 100 \mathrm{~g})$ & 32 & 84 & 232 \\
Catechin $(\mathrm{mg} / 100 \mathrm{~g})$ & 28 & 705 & 92 \\
Procyanidin oligomers & 130 & & 740 \\
$\quad$ (dimers to decamers) $(\mathrm{mg} / 100 \mathrm{~g})$ & & & \\
\hline
\end{tabular}


or gall bladder problems. Exclusion criteria were as follows: those on a weight-reducing dietary regimen; taking any dietary supplements; consuming more than fifteen units (120 g) of alcohol per week; taking anti-inflammatory or blood pressure-lowering medication; smokers or those with sensitivities to chocolate, reduced-energy sweeteners, dairy products, nuts or gluten; vegetarians or vegans. Volunteers were instructed not to alter their usual dietary or fluid intakes during their participation in the study. Those selected were required to refrain from the following for $24 \mathrm{~h}$ before the start of the study: consumption of flavonoid-rich foods including many fruits and vegetables, cocoa, chocolate, tea, coffee and alcohol, and were provided with a low-flavonoid meal (low-fat macaroni cheese) for consumption the evening before the study days.

\section{Study design}

The study was conducted according to the guidelines laid down in the Declaration of Helsinki and all procedures involving human subjects were approved by the University of Reading Research Ethics Committee (reference no. 08/08). The study was also registered with the National Institutes of Health-randomised trial records held on the National Institutes of Health ClinicalTrials.gov website (NCT01292967). The study was a randomised, double-blind, three-arm cross-over study design and consisted of three intervention arms of $5 \mathrm{~h}$ each, separated by a 1-week washout period. Each arm was preceded by a $24 \mathrm{~h}$ low-flavonoid diet and subjects were asked to fast for $12 \mathrm{~h}$ before each intervention day. During each intervention period, participants consumed a high-flavanol chocolate containing maltitol, a high-flavanol chocolate containing sucrose or a low-flavanol chocolate containing sucrose. The order of administration was randomly assigned. On each study day, subjects were cannulated and baseline blood samples were collected. After consumption of the test chocolate, blood samples $(20 \mathrm{ml})$ were collected at 1, 2 and $4 \mathrm{~h}$ post-consumption. All chocolates were well tolerated by the volunteers and there were no reports of gastrointestinal problems related to the ingestion of any of the products, including the maltitol-containing product. Indeed, total maltitol ingestion was approximately $10 \mathrm{~g}$, which was below the $40 \mathrm{~g}$ where adverse gastrointestinal effects have been reported $^{(39)}$.

\section{Plasma sample preparation}

Due to the lack of authentic flavanol metabolite standards, plasma samples were prepared using enzymatic hydrolysis with $\beta$-glucuronidase and sulfatase, as described previously ${ }^{(40)}$. After enzymatic hydrolysis, glucuronidated and sulphated flavanols were converted into unmethylated, $3^{\prime}$-O-methylated and 4'-O-methylated flavanol metabolites. To ensure that the hydrolysis of the flavanol metabolites was complete, this procedure was validated with the use of 4-nitrophenyl$\beta$-D-glucuronic acid and nitrocatechol sulphate (data not shown). The validation with authentic flavanol standards has also been reported previously ${ }^{(40)}$. Briefly, blood samples were immediately processed to isolate plasma and ascorbic acid $(1 \mathrm{mg} / \mathrm{ml})$ was added to each before storage (at $-80^{\circ} \mathrm{C}$ ). Before analysis, $1 \mathrm{ml}$ of plasma was defrosted on ice and subjected to $\beta$-glucuronidase and sulfatase treatment (10000 units $\beta$-glucuronidase, 300 units sulfatase, $40 \mathrm{~min}$; $37^{\circ} \mathrm{C}$ ) to produce non-glucuronidated and non-sulphated metabolites for analysis. Then, samples were mixed with $2 \mathrm{ml}$ of acidified ice-cold methanol (0.5\% acetic acid in methanol, v/v) containing $3^{\prime}$-O-ethyl-(-)-epicatechin (500 nm) as a recovery standard. Samples were centrifuged at $17000 \mathrm{~g}$ for $15 \mathrm{~min}$ at $4^{\circ} \mathrm{C}$ and the supernatant was collected. The pellet was extracted again with $2 \mathrm{ml}$ of acidified ice-cold methanol $(0.5 \%$ acetic acid in methanol, $\mathrm{v} / \mathrm{v})$ containing $3^{\prime}$-O-ethyl-(-)-epicatechin ( $\left.500 \mathrm{~nm}\right)$, and then with $1 \mathrm{ml}$ of $50 \%$ methanol acidified with $0.5 \%$ acetic acid and containing 3'-O-ethyl-(-)-epicatechin (500 nm). Combined supernatants underwent concentration (to approximately $50 \mu \mathrm{l}$ ) using a Speedvac system (Thermo Fisher Scientific, Inc.) and were mixed with resorcinol $(300 \mathrm{pmol})$ and catechol $(300 \mathrm{pmol})$ (internal standards) before analysis by HPLC.

\section{Flavanol quantification by HPLC-fluorescence detection/UV}

Plasma samples were analysed for flavanol metabolites by the HPLC-fluorescence detection/UV technique, as described previously ${ }^{(40)}$. Flavanol monomers and O-methylated metabolites were analysed using a Hewlett-Packard 1200 series HPLC (Hewlett-Packard) equipped with a diode array and fluorescence detector. Samples $(50 \mu \mathrm{l})$ were injected onto a reversed-phase Phenomenex Luna C18(2) column $(4.6 \times 150 \mathrm{~mm})$ with $3 \mu \mathrm{m}$ particle size. The mobile phase consisted of (A) HPLC-grade water, (B) 200 mm-sodium acetate ( $\mathrm{pH}$ 4.4)-methanol (84:16) and (C) acetonitrile, and the following gradient protocol was run: $0 \mathrm{~min}, 75 \% \mathrm{~A}, 25 \% \mathrm{~B}$; $5 \min , 75 \%$ A, 25\% B; $20 \min , 65 \%$ A, 25\% B; $28 \mathrm{~min}, 63 \%$ A, $25 \% \mathrm{~B} ; 34 \mathrm{~min}, 55 \% \mathrm{~A}, 25 \% \mathrm{~B} ; 41 \mathrm{~min}, 45 \% \mathrm{~A}, 25 \% \mathrm{~B}$; $45 \mathrm{~min}, 25 \% \mathrm{~B}, 75 \% \mathrm{C} ; 55 \mathrm{~min}, 25 \% \mathrm{~B}, 75 \% \mathrm{C} ; 56.1 \mathrm{~min}$, $75 \% \mathrm{~A}, 25 \% \mathrm{~B} ; 60 \mathrm{~min}, 75 \% \mathrm{~A}, 25 \% \mathrm{~B}$. The flow rate was $0.8 \mathrm{ml} / \mathrm{min}$. Detection of flavanols and their metabolites was performed using a fluorescence detector with an excitation wavelength of $276 \mathrm{~nm}$ and an emission wavelength of $316 \mathrm{~nm}$. The concentration of each compound was determined using an external calibration curve produced with the use of authentic standards.

\section{Statistical analysis}

Mixed models were fitted to analyse the data using SAS version 9.1 (SAS Institute). The outcome variables were epicatechin, 3'-O-methyl-epicatechin (3ME) and 4'-O-methylepicatechin (4ME). The subject was considered a random effect to explain the correlation of the observations at different times within subjects. For $3 \mathrm{ME}$, a logarithmic transformation was needed in order to validate the model. For $4 \mathrm{ME}$, a Box-Cox transformation was applied with $\alpha=0.3$ (the outcome variable $4 \mathrm{ME}$ was transformed to $4 \mathrm{ME}^{0.3}$ ). The AUC and the peak plasma concentration of flavanols (maximum 
concentration, $C_{\max }$ ) were calculated according to noncompartmental models.

\section{Results}

No flavanols were detected in the plasma samples of any of the subjects at baseline or following the consumption of the low-flavanol chocolate, suggesting that all volunteers complied with the $24 \mathrm{~h}$ low-flavonoid diet before the study day (Fig. 1). Unmethylated epicatechin, $3 \mathrm{ME}$ and $4 \mathrm{ME}$ metabolites were detected in all plasma samples of subjects who had consumed either of the high-flavanol test chocolates (Figs. 1 and 2). In contrast, no catechin, 3'-O-methyl-catechin or $4^{\prime}$-O-methyl-catechin metabolites were detected following the consumption of any of the test chocolates. The plasma levels of unmethylated epicatechin metabolites $(P=0.0002)$,
3ME $(P=0.0304)$ and 4ME $(P=0.0397)$ metabolites were significantly higher at 1 and $2 \mathrm{~h}$ after consumption of the sugar-containing test chocolate compared with following the consumption of the maltitol-containing test chocolate (Fig. 2). Furthermore, consumption of the sucrose-containing test chocolate resulted in a 19\% higher total AUC and $17 \%$ higher $C_{\max }$ for plasma unmethylated epicatechin compared with its maltitol equivalent (Table 2). However, this was not the case for $3 \mathrm{ME}$ or $4 \mathrm{ME}$ derivatives, where there were no significant differences $(P>0 \cdot 05)$. There was no significant difference in the maximum time $\left(T_{\max }\right)$ between the two high-flavanol containing test chocolates with respect to epicatechin, 3ME and 4ME ( $P>0.05$; Table 2).

The differences in absorption characteristics between the sucrose-containing and maltitol-containing chocolates were also reflected in the total plasma flavanol levels (Fig. 3). At 1
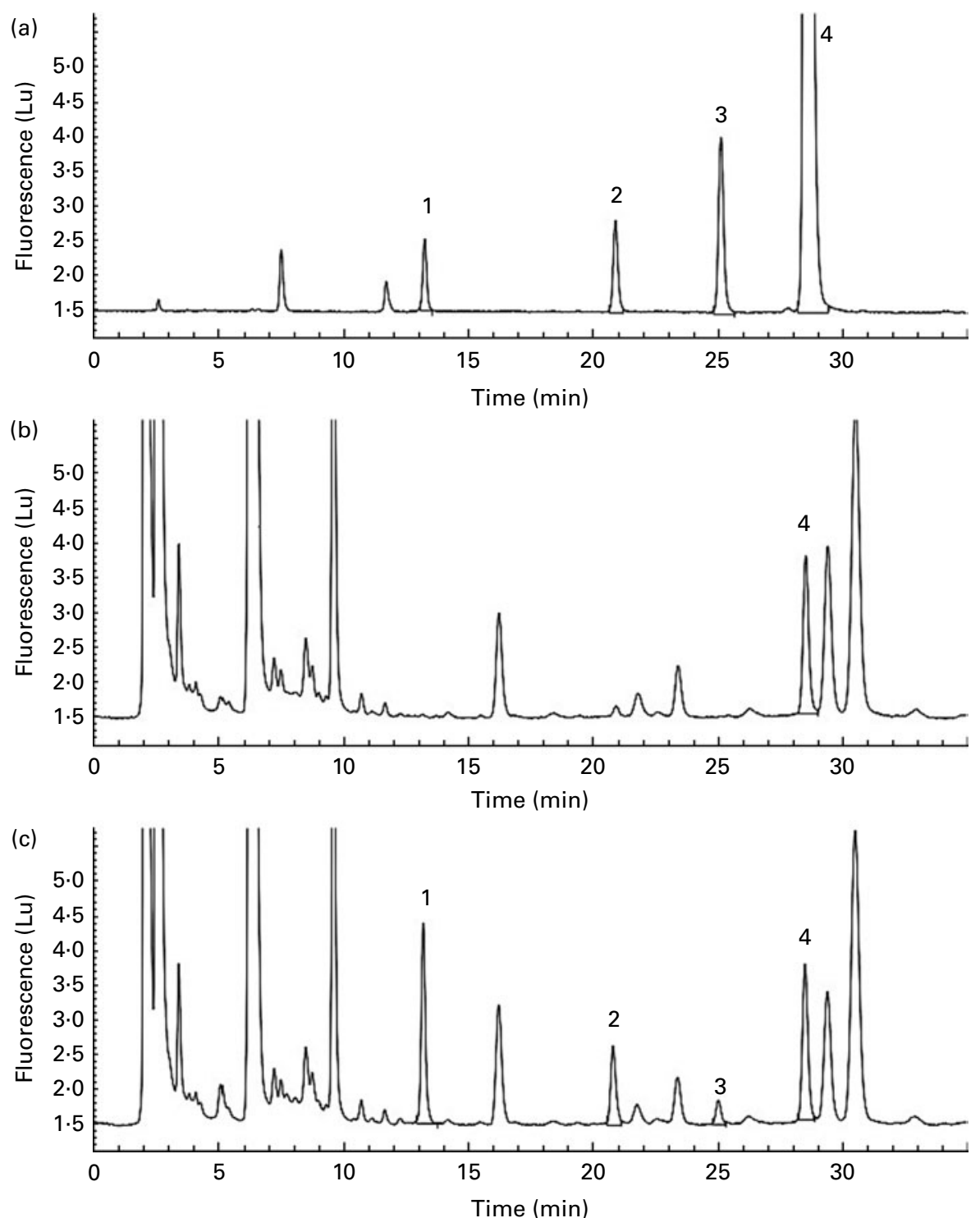

Fig. 1. HPLC chromatograms of (a) standards of unmethylated (peak 1), 3'-O-methylated (peak 2) and 4'-O-methylated (peak 3 ) (-)-epicatechin and the recovery standard $3^{\prime}-O$-ethyl-(-)-epicatechin (peak 4); enzymatic treated plasma samples (b) before and (c) after $2 \mathrm{~h}$ of consumption of the sugar-containing high-flavanol chocolate bar. Detection of flavanol metabolites was performed using a fluorescence detector with an excitation wavelength of $276 \mathrm{~nm}$ and an emission wavelength of $316 \mathrm{~nm}$. 
(a)

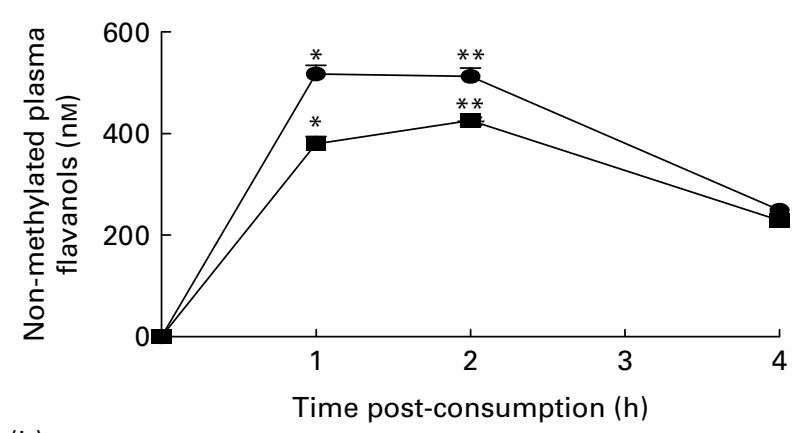

(b)

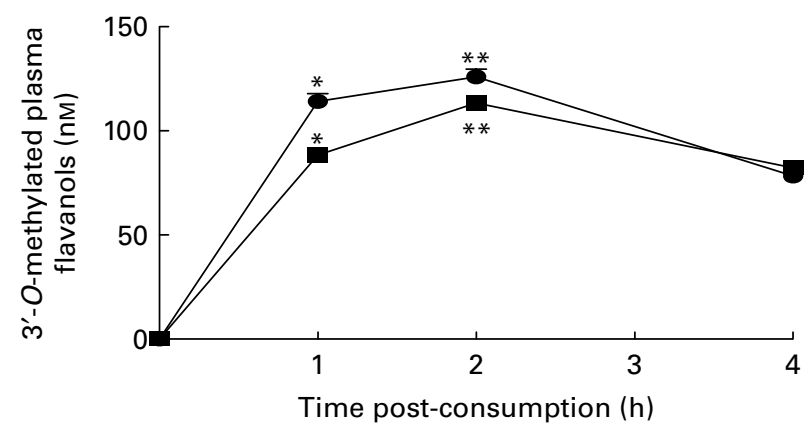

(c)

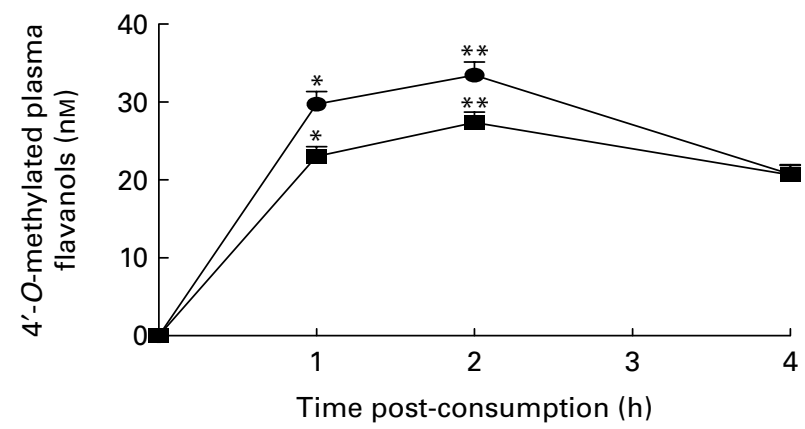

Fig. 2. (a) Unmethylated, (b) $3^{\prime}-O$-methylated and (c) 4'-O-methylated epicatechin metabolites in the plasma before $(0 \mathrm{~h})$ and after $(1,2$ and $4 \mathrm{~h})$ consumption of the sugar-containing $(-\bullet)$ and maltitol-containing $(-\mathbf{-})$ high-flavanol chocolate bar. Values are mean plasma concentrations, with their standard errors represented by vertical bars $\left(n\right.$ 15). ${ }^{*, * *}$ Mean values were significantly different for non-methylated epicatechin $(P=0.002)$, $3^{\prime}$-O-methyl-epicatechin $(P=0.0304)$ and $4^{\prime}-O$-methyl-epicatechin $(P=0.0397)$ plasma metabolites between the sugar-containing and maltitol-containing high-flavanol chocolate bars.

and $2 \mathrm{~h}$ post-consumption, the total plasma flavanol concentrations were 26 and $17 \%$ higher, respectively, after consumption of the sucrose-containing chocolate compared with following the maltitol-containing one $(P=0.0001$ and $P=0 \cdot 0102$, respectively). However, this difference was no longer evident at $4 \mathrm{~h}$ post-consumption $(P=0 \cdot 6830)$.

\section{Discussion}

The general kinetics of absorption, metabolism and plasma concentration of flavanols reported here are consistent with previous studies using similar chocolate/cocoa interventions ${ }^{(19,41-44)}$. However, despite these similarities, there were significant differences in the relative absorption of flavanols as a function of the type of chocolate product consumed. The sugar alcohol maltitol is a commonly used sucrose alternative, as it delivers less energy per $\mathrm{g}(8 \cdot 8 \mathrm{~kJ} / \mathrm{g}(2 \cdot 1 \mathrm{kcal} / \mathrm{g})$ compared with $16.8 \mathrm{~kJ} / \mathrm{g}(4.0 \mathrm{kcal} / \mathrm{g}))$ and does not contribute to tooth decay ${ }^{(45)}$. The present data indicate that consumption of flavanols in a product containing maltitol rather than sucrose results in a significantly lower level of total flavanol absorption and a lower peak plasma concentration of unmethylated epicatechin metabolites. As the primary difference between the two high-flavanol-containing test chocolates used in the present study was their carbohydrate content and thus their total energy load (Table 1), the present data suggest that the carbohydrate composition of the food matrix is an important determinant for total flavanol absorption in the small intestine. However, carbohydrate type and/or energy did not have a significant impact on the $O$-methylation pattern observed for absorbed flavanols, suggesting that while total absorption was affected, catechol-O-methyltransferase metabolic activity was unchanged. Previous investigations into the influence of carbohydrate on flavanol absorption were inconclusive ${ }^{(29,32)}$, primarily due to the use of inadequate control interventions or the relatively low amounts of flavanols in the test materials. With respect to the latter, flavanol absorption appears to be influenced by the food matrix to a greater degree if flavanol levels are low $(6.7 \mathrm{mg}$ epicatechin, $70 \mathrm{mg}$ procyanidins per cocoa drink) ${ }^{(28)}$. However, in the case of most commercially available dark chocolates, the level of CF is indeed closer to that used in the present study (54 mg epicatechin, $251 \mathrm{mg}$ of total CF per bar) ${ }^{(46,47)}$.

A limitation of the present study is that plasma flavanols were quantified only $4 \mathrm{~h}$ post-consumption. As such, it is unclear whether plasma flavanol levels post- $4 \mathrm{~h}$ would follow the same profile. However, the maximum level of plasma epicatechin metabolites was found between 1 and $2 \mathrm{~h}$ after flavanol intake, and by $4 \mathrm{~h}$, plasma epicatechin metabolites were low (Fig. 2), suggesting that it is unlikely the plasma flavanol levels post- $4 \mathrm{~h}$ will greatly contribute to the total plasma flavanol load. The well-reported laxative effect of maltitol may be one explanation for the decrease in flavanol absorption ${ }^{(48)}$, although no gastrointestinal problems were reported among the volunteers of the present study. Polyols undergo negligible absorption in the small intestine, thus causing symptoms of gastrointestinal intolerance, such as increased intestinal transit times, bloating or diarrhoea ${ }^{(49)}$. Despite this, maltitol, when used at a dose three times higher than the present study $(30 \mathrm{~g})$, has been found not to induce gastrointestinal symptoms ${ }^{(39,48,50)}$. Nevertheless, maltitol may act to limit flavanol absorption due to its effect on the osmolarity of the small-intestinal contents. In the jejunum, nutrient absorption is the major driving force for water absorption $^{(51)}$ and non-absorbable solutes that remain within the intestinal lumen produce an osmotic pressure that may limit water absorption. For example, lactulose, a non-digestible sugar commonly used as a laxative, has been shown to impair drug absorption in healthy volunteers, something that was partially reversed by the co-administration of sucrose ${ }^{(51)}$. Maltitol has previously been reported to reduce the absorption 
Table 2. Pharmacokinetic parameters of flavanol absorption

\begin{tabular}{|c|c|c|c|c|c|c|}
\hline & \multicolumn{3}{|c|}{ Maltitol high-flavanol bar } & \multicolumn{3}{|c|}{ Sucrose high-flavanol bar } \\
\hline & EC & 3ME & 4ME & EC & $3 \mathrm{ME}$ & $4 \mathrm{ME}$ \\
\hline AUC $(\mathrm{nmol} \times \mathrm{h} / \mathrm{l})$ & $1247 \cdot 2$ & 340.5 & 84.7 & $1535 \cdot 4^{*}$ & $381 \cdot 2$ & $100 \cdot 6$ \\
\hline$C_{\max }(\mathrm{nmol} / \mathrm{l})$ & $464 \cdot 3$ & 114.9 & 29.5 & $559 \cdot 9^{*}$ & $132 \cdot 8$ & $37 \cdot 2$ \\
\hline$T_{\max }(\mathrm{h})$ & 2 & 2 & 2 & 2 & 2 & 2 \\
\hline
\end{tabular}

EC, epicatechin; 3ME, 3'-O-methyl-epicatechin; 4ME, 4'-O-methyl-epicatechin; AUC, area under the curve; $C_{\max }$, maximum concentration; $T_{\max }$, maximum time.

*Value was significantly different from that for EC for the maltitol high-flavanol bar $(p<0.05)$.

of nutrients in the small intestine ${ }^{(52)}$, thus the absorption of flavanols may also be affected by the presence of maltitol. Lastly, although the absorption of flavanols, and, indeed, other flavonoids, is considered to occur by a process of passive absorption ${ }^{(53,54)}$, we cannot rule out that the greater amount of energy delivered with the sugar-containing food may have an impact on metabolic events in enterocytes, thus facilitating greater transfer from the lumen to the portal blood. Further research is needed to elucidate the precise mechanisms by which maltitol limits the absorption of CF in the small intestine.

As the vascular benefits of flavanol-containing foods are dependent on the delivery of flavanols to the systemic circulation $^{(21,31,18,55)}$, factors affecting their absorption and metabolism, including food matrix components such as carbohydrate, represent important considerations in the design of new products aimed to support cardiovascular health. However, while the present data suggest that the use of a replacement sugar, such as maltitol, may reduce flavanol absorption, at present, it is unclear as to whether this approximate $20 \%$ reduction in flavanol absorption would have an impact on beneficial vascular responses. Although plasma flavanol levels were not measured, previous data suggest that sugar-free cocoa may improve endothelial function in overweight adults to a greater degree than regular or sugarsweetened cocoa $^{(31,56)}$. While this result may appear to be counter-intuitive to the present findings, there is also clear

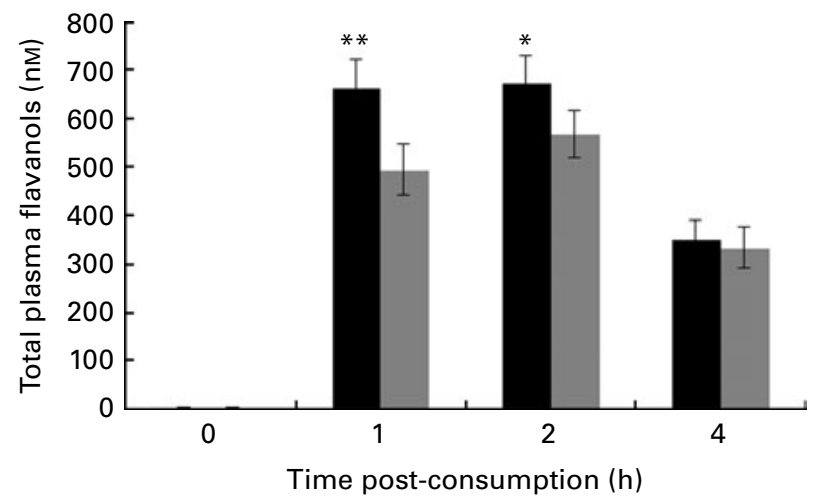

Fig. 3. Total plasma flavanol levels before $(0 \mathrm{~h})$ and after (1, 2 and $4 \mathrm{~h})$ consumption of the sugar-containing ( $\square$ ) and maltitol-containing ( $\square$ ) high-flavanol chocolate bars. Values are mean plasma concentrations, with their standard errors represented by vertical bars $(n 15)$. Mean value was significantly different from that for the maltitol high-flavanol bar: ${ }^{\star} P=0.0102,{ }^{\star \star} P=0.001$. evidence that flavanol-induced improvements in endothelial function are dose-dependent with respect to plasma levels of (-)-epicatechin ${ }^{(18)}$. Furthermore, sugar-free cocoa might be expected to induce a greater vascular effect than a maltitol-containing equivalent, as it would not be expected to influence intestinal osmolarity and thus flavanol absorption. Further work is warranted in order to investigate the impact of low-energy, sucrose replacements on the vascular efficacy of a food in addition to its effects on the absorption of CF.

Despite the findings reported here and elsewhere in the literature, from the point of view of public health nutrition, recommending chocolate consumption, as part of a healthy diet, is controversial, as chocolate, while potentially high in flavanols, is also high in sugar and saturated fats. An increase in chocolate consumption might lead to detrimental effects in cardiovascular health and increases in body weight. As such, any future exploitation of the health effects of $\mathrm{CF}$ requires additional work in order to develop nutritionally responsible food matrices designed with optimal flavanol delivery to the vascular system in mind.

\section{Acknowledgements}

We thank Dr Javier I. Ottaviani from the University of California at Davis, for his help with the analytical work and for useful discussions. We also thank the study participants for taking part in the study. This study was supported by an unrestricted grant from Mars, Inc. (Hackettstown, NJ, USA). A. R.-M. and J. P. E. S. are senior investigators in the FLAVIOLA research consortium of the European Union (FP7-KBBE-2008-2B). The authors responsibilities were as follows: A. R.-M., J. P. E. S. and C. K.-U. designed the research; A. R.-M. conducted the research and analysed the data; A. R.-M., J. P. E. S., M. J. O.-C. and C. K.-U. wrote the paper; A. V. performed the statistical analysis of the data. All authors read and approved the final manuscript. The authors declare that they have no conflicts of interest.

\section{References}

1. Arts IC, Jacobs DR Jr, Harnack LJ, et al. (2001) Dietary catechins in relation to coronary heart disease death among postmenopausal women. Epidemiology 12, 668-675.

2. Hertog MG, Feskens EJ, Hollman PC, et al. (1993) Dietary antioxidant flavonoids and risk of coronary heart disease: the Zutphen Elderly Study. Lancet 342, 1007-1011. 
3. Knekt P, Jarvinen R, Reunanen A, et al. (1996) Flavonoid intake and coronary mortality in Finland: a cohort study. BMJ 312, 478-481.

4. Mink PJ, Scrafford CG, Barraj LM, et al. (2007) Flavonoid intake and cardiovascular disease mortality: a prospective study in postmenopausal women. Am J Clin Nutr 85, 895-909.

5. Arts IC, Hollman PC, Feskens EJ, et al. (2001) Catechin intake might explain the inverse relation between tea consumption and ischemic heart disease: the Zutphen Elderly Study. $A m$ J Clin Nutr 74, 227-232.

6. Buijsse B, Feskens EJ, Kok FJ, et al. (2006) Cocoa intake, blood pressure, and cardiovascular mortality: the Zutphen Elderly Study. Arch Intern Med 166, 411-417.

7. Cassidy A, O'Reilly EJ, Kay C, et al. (2011) Habitual intake of flavonoid subclasses and incident hypertension in adults. Am J Clin Nutr 93, 338-347.

8. Hertog MG, Kromhout D, Aravanis C, et al. (1995) Flavonoid intake and long-term risk of coronary heart disease and cancer in the seven countries study. Arch Intern Med 155, 381-386.

9. Hooper L, Kroon PA, Rimm EB, et al. (2008) Flavonoids, flavonoid-rich foods, and cardiovascular risk: a meta-analysis of randomized controlled trials. Am J Clin Nutr 88, 38-50.

10. Landberg R, Sun Q, Rimm EB, et al. (2011) Selected dietary flavonoids are associated with markers off inflammation and endothelial dysfunction in US women. $J$ Nutr 141, 618-625.

11. Lee KW, Kim YJ, Lee HJ, et al. (2003) Cocoa has more phenolic phytochemicals and a higher antioxidant capacity than teas and red wine. J Agric Food Chem 51, 7292-7295.

12. Taubert D, Roesen R, Lehmann C, et al. (2007) Effects of low habitual cocoa intake on blood pressure and bioactive nitric oxide: a randomized controlled trial. JAMA 298, 49-60.

13. Buijsse B, Weikert C, Drogan D, et al. (2010) Chocolate consumption in relation to blood pressure and risk of cardiovascular disease in German adults. Eur Heart J 31, 1616-1623.

14. Heiss C \& Kelm M (2010) Chocolate consumption, blood pressure, and cardiovascular risk. Eur Heart $J$ 31, $1554-1556$

15. Ried K, Sullivan T, Fakler P, et al. (2010) Does chocolate reduce blood pressure? A meta-analysis. BMC Med $\mathbf{8}, 39$.

16. Engler MB, Engler MM, Chen CY, et al. (2004) Flavonoid-rich dark chocolate improves endothelial function and increases plasma epicatechin concentrations in healthy adults. $J$ Am Coll Nutr 23, 197-204.

17. Heiss C, Dejam A, Kleinbongard P, et al. (2003) Vascular effects of cocoa rich in flavan-3-ols. JAMA 290, 1030-1031.

18. Heiss C, Finis D, Kleinbongard P, et al. (2007) Sustained increase in flow-mediated dilation after daily intake of high-flavanol cocoa drink over 1 week. $J$ Cardiovasc Pharmacol 49, 74-80.

19. Schroeter H, Heiss C, Balzer J, et al. (2006) (-)-Epicatechin mediates beneficial effects of flavanol-rich cocoa on vascular function in humans. Proc Natl Acad Sci U S A 103, 1024-1029.

20. Balzer J, Rassaf T, Heiss C, et al. (2008) Sustained benefits in vascular function through flavanol-containing cocoa in medicated diabetic patients a double-masked, randomized, controlled trial. J Am Coll Cardiol 51, 2141-2149.

21. Heiss C, Jahn S, Taylor M, et al. (2010) Improvement of endothelial function with dietary flavanols is associated with mobilization of circulating angiogenic cells in patients with coronary artery disease. J Am Coll Cardiol 56, 218-224.

22. Murphy KJ, Chronopoulos AK, Singh I, et al. (2003) Dietary flavanols and procyanidin oligomers from cocoa
(Theobroma cacao) inhibit platelet function. Am J Clin Nutr 77, 1466-1473.

23. Pearson DA, Paglieroni TG, Rein D, et al. (2002) The effects of flavanol-rich cocoa and aspirin on ex vivo platelet function. Thromb Res 106, 191-197.

24. Ostertag LM, O'Kennedy N, Kroon PA, et al. (2010) Impact of dietary polyphenols on human platelet function-a critical review of controlled dietary intervention studies. Mol Nutr Food Res 54, 60-81.

25. Mao TK, van de Water J, Keen CL, et al. (2002) Modulation of TNF-alpha secretion in peripheral blood mononuclear cells by cocoa flavanols and procyanidins. Dev Immunol $\mathbf{9}$, 135-141.

26. Monagas M, Khan N, Andres-Lacueva C, et al. (2009) Effect of cocoa powder on the modulation of inflammatory biomarkers in patients at high risk of cardiovascular disease. Am J Clin Nutr 90, 1144-1150.

27. Katz DL, Doughty K \& Ali A (2011) Cocoa and chocolate in human health and disease. Antioxid Redox signal 15, 2779-2811

28. Mullen W, Borges G, Donovan JL, et al. (2009) Milk decreases urinary excretion but not plasma pharmacokinetics of cocoa flavan-3-ol metabolites in humans. Am J Clin Nutr 89, 1784-1791.

29. Schramm DD, Karim M, Schrader HR, et al. (2003) Food effects on the absorption and pharmacokinetics of cocoa flavanols. Life Sci 73, 857-869.

30. Urpi-Sarda M, Monagas M, Khan N, et al. (2009) Epicatechin, procyanidins, and phenolic microbial metabolites after cocoa intake in humans and rats. Anal Bioanal Chem 394, $1545-1556$.

31. Faridi Z, Njike VY, Dutta S, et al. (2008) Acute dark chocolate and cocoa ingestion and endothelial function: a randomized controlled crossover trial. Am J Clin Nutr 88, 58-63.

32. Neilson AP, George JC, Janle EM, et al. (2009) Influence of chocolate matrix composition on cocoa flavan-3-ol bioaccessibility in vitro and bioavailability in humans. $J$ Agric Food Chem 57, 9418-9426.

33. Neilson AP, Sapper TN, Janle EM, et al. (2010) Chocolate matrix factors modulate the pharmacokinetic behavior of cocoa flavan-3-ol phase II metabolites following oral consumption by Sprague-Dawley rats. J Agric Food Chem 58, 6685-6691.

34. Roura E, Andres-Lacueva C, Estruch R, et al. (2007) Milk does not affect the bioavailability of cocoa powder flavonoid in healthy human. Ann Nutr Metab 51, 493-498.

35. Schroeter H, Holt RR, Orozco TJ, et al. (2003) Nutrition: milk and absorption of dietary flavanols. Nature 426, 787-788, discussion 788.

36. Roura E, Andres-Lacueva C, Estruch R, et al. (2008) The effects of milk as a food matrix for polyphenols on the excretion profile of cocoa (-)-epicatechin metabolites in healthy human subjects. Br J Nutr 100, 846-851.

37. Keogh JB, McInerney J \& Clifton PM (2007) The effect of milk protein on the bioavailability of cocoa polyphenols. J Food Sci 72, S230-S233

38. Serafini M, Bugianesi R, Maiani G, et al. (2003) Plasma antioxidants from chocolate. Nature 424, 1013.

39. Storey DM, Koutsou GA, Lee A, et al. (1998) Tolerance and breath hydrogen excretion following ingestion of maltitol incorporated at two levels into milk chocolate consumed by healthy young adults with and without fasting. $J$ Nutr 128, 587-592.

40. Ottaviani JI, Momma TY, Heiss C, et al. (2011) The stereochemical configuration of flavanols influences the level 
and metabolism of flavanols in humans and their biological activity in vivo. Free Radic Biol Med 50, 237-244.

41. Richelle M, Tavazzi I, Enslen M, et al. (1999) Plasma kinetics in man of epicatechin from black chocolate. Eur J Clin Nutr 53, 22-26.

42. Wang JF, Schramm DD, Holt RR, et al. (2000) A doseresponse effect from chocolate consumption on plasma epicatechin and oxidative damage. J Nutr 130, 2115S-2119S.

43. Rein D, Lotito S, Holt RR, et al. (2000) Epicatechin in human plasma: in vivo determination and effect of chocolate consumption on plasma oxidation status. J Nutr 130, 2109S-2114S.

44. Holt RR, Lazarus SA, Sullards MC, et al. (2002) Procyanidin dimer B2 [epicatechin-(4beta-8)-epicatechin] in human plasma after the consumption of a flavanol-rich cocoa. $A m$ J Clin Nutr 76, 798-804.

45. Ooshima T, Izumitani A, Minami T, et al. (1992) Noncariogenicity of maltitol in specific pathogen-free rats infected with mutans streptococci. Caries Res 26, 33-37.

46. Miller KB, Hurst WJ, Flannigan N, et al. (2009) Survey of commercially available chocolate- and cocoa-containing products in the United States. 2. Comparison of flavan-3-ol content with nonfat cocoa solids, total polyphenols, and percent cacao. J Agric Food Chem 57, 9169-9180.

47. Langer S, Marshall LJ, Day AJ, et al. (2011) Flavanols and methylxanthines in commercially available dark chocolate: a study of the correlation with nonfat cocoa solids. J Agric Food Chem 59, 8435-8441.
48. Ruskone-Fourmestraux A, Attar A, Chassard D, et al. (2003) A digestive tolerance study of maltitol after occasional and regular consumption in healthy humans. Eur J Clin Nutr $\mathbf{5 7}, 26-30$.

49. Livesey G (2001) Tolerance of low-digestible carbohydrates: a general view. Br J Nutr 85, Suppl. 1, S7-16.

50. Koutsou GA, Storey DM, Lee A, et al. (1996) Dose-related gastrointestinal response to the ingestion of either isomalt, lactitol or maltitol in milk chocolate. Eur J Clin Nutr 50, $17-21$.

51. Riley SA, Kim M, Sutcliffe F, et al. (1992) Effects of a non-absorbable osmotic load on drug absorption in healthy volunteers. Br J Clin Pharmacol 34, 40-46.

52. Langkilde AM, Andersson H, Schweizer TF, et al. (1994) Digestion and absorption of sorbitol, maltitol and isomalt from the small bowel. A study in ileostomy subjects. Eur J Clin Nutr 48, 768-775.

53. Spencer JP, Chowrimootoo G, Choudhury R, et al. (1999) The small intestine can both absorb and glucuronidate luminal flavonoids. FEBS Lett 458, 224-230.

54. Tian XJ, Yang XW, Yang X, et al. (2009) Studies of intestinal permeability of 36 flavonoids using Caco-2 cell monolayer model. Int J Pharm 367, 58-64.

55. Heiss C, Keen CL \& Kelm M (2010) Flavanols and cardiovascular disease prevention. Eur Heart J 31, 2583-2592.

56. Njike VY, Faridi Z, Shuval K, et al. (2011) Effects of sugarsweetened and sugar-free cocoa on endothelial function in overweight adults. Int J Cardiol 149, 83-88. 